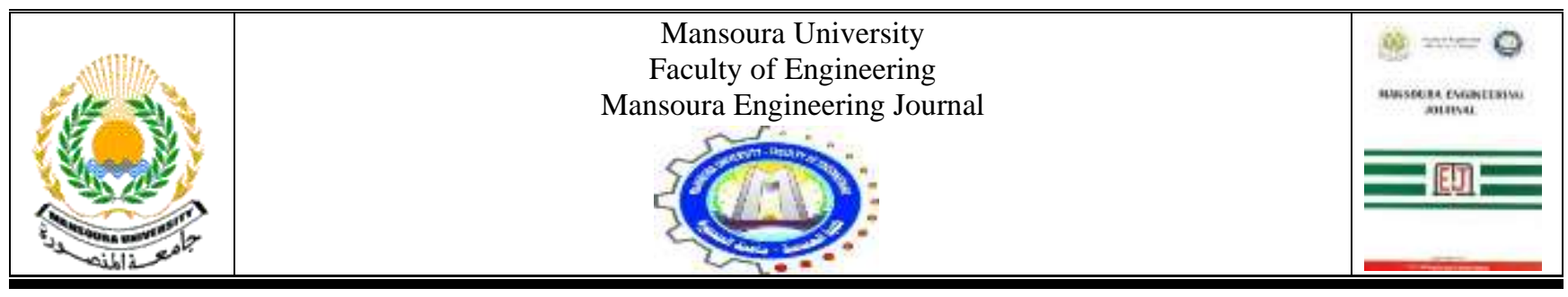

\title{
The Use of Sustainable Materials in the Rurban Communities in Egypt
}

\author{
Rola Kamal Ali, M. G. Mousa and Sherif Ahmed Sheta
}

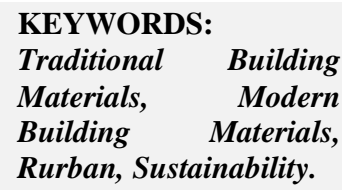

\section{INTRODUCTION}

$r$

DHE existening problems in the rural area in Egypt such as the use of concrete in building construction have lead to their radical conversion into small urban centers gradually. This in turn, has lead to comprehensive societal changes which include the socioeconomic change. Increased concrete use has been witnessed every year in rural areas, which causes climatic hazards, driving more attraction toward alternative traditional building materials and sustainable solutions. In the meantime, the use of modern materials can be an engine for sustainable development, if handled well, with understanding of the modernization patterns in building construction towards the

Received: (11 December, 2019) - Revised: (25 August, 2020) - Accepted: (8 September, 2020)

Rola Kamal Ali, M.Sc. Candidate, Programme of Environmental Engineering, Management and Technology, Faculty of Engineering, Mansoura University (e-mail: rolakamal86@hotmail.com).

M. G. Mousa, Professor of Mechanical Engineering Department, Faculty of Engineering, Mansoura University (e-mail: mgmousa@gmail.com).

Sherif Ahmed Sheta, Vice Dean for Education and Students Affairs, Faculty of Fine Arts, Mansoura University (e-mail: sheriefsheta@gmail.com). desired typology of rural sustainability.

The main aim of this research is to analyze and evaluate traditional vs. modern building materials and the different between it. The methodology of research is based on "The inductive approach in theoretical studies and the use of deductive approach through analysis and comparative analysis" to arrive at an evaluation of the use of traditional building materials versus modern building materials.

To realize the aim, three main methodological steps are undertaken to achieve the following:

1. examining and defining the conception of traditionalism vs. modernization in building materials selection and use.

2. Studying the different types of modernization patterns in building constructions for rurban communities FROM Sustainability PERSPECTIVE.

3. setting a sustainability-based comparison between traditional and modern building materials in the rurban communities of Egypt.

The hypothesis of the paper is "The possibility of using traditional building materials to achieve sustainability in the rurban in Egypt." 


\section{TRADITIONALISM AND MODERNIZATION MATERIALS CONCEPTION}

The classification of building materials according to modern and traditional materials stimulates the necessity of comparing the two typologies. In another words, what is considered to be modern or to be traditional varies from culture to culture and from time to time. However, in present time, concrete has become the principal material in modern construction practices.

Rural Egypt has long witnessed a trend towards the increasing modernization since the use of concrete in residential buildings substantially increased. Furthermore, significant urban versus rural disparities were revealed, although in rural environments can generally find use for the material construction. Anyway, as a consequence of the above described "modernization" process, Egyptian Villages have been rapidly changing. Not only are the socio-economic composition of the population, but also the physical structure of the villages are being transformed [1].

According to Nicchia, the building sector only was responsible for the emission of about $23-40 \%$ of the world greenhouse gases in 2016 (Nicchia, R., 2010). This is plausible owing to the various non environmental friendly materials used by modern building industry and the palpable contemporary design construct. Unlike modern buildings, traditional building materials are proven to be earth conscious and have nearly zero carbon footprints [2]. Such aspects were emphasised with the policy of natural self-sufficiency forcing architecture to search within local resources [3]. Yet, the modernist building sector with its insatiable drive for autonomy has relegated lessons from traditional building to being primitive. Moreover, the absence of objects of industrialisation has been defined as forming conformity with poverty [4].

When the continuity was the guiding principle, the structural work within the site retained traditional building methods, above all made extensive use of locally available materials. Traditional building materials and design have gained renewed attention in the green building movement, thanks to the use of locally accessible resources that address local conditions in a cost-effective way[5].

Many traditional building materials have benefited from innovative technologies in both manufacture and application. These developments have made several traditional building materials more financially feasible, environmental friendly and technically sound [6].

Grandi suggests that change is not the problem; whereas resistance to change is the main issue. He clarifies that when a change is introduced to rural community, with a lot of environmental conceptions, resistance to change is minimized. Resistance is also minimized if there is a wide-spread belief that a change is needed. But if they lack a belief that they can indeed change; their efforts are not likely to succeed. Although that the human behavior develops automatically, even in the absence of guidance and support [7]. The cultural competency requirements should be apparent from the beginning of the preparing process that suits of community conditions [8]. Also, have not reliance upon other culture, because any culture included deep-rooted traditions [9].

\section{MODERNIZATION PATTERNS IN BUILDING CONSTRUCTIONS AND MATERIAL USE}

Based on the above, Fig. 1. illustrates that modernization patterns in the building constructions from sustainability perspective that can be divided into three categories: traditional, rapid gradual transformation and prompt modernization.

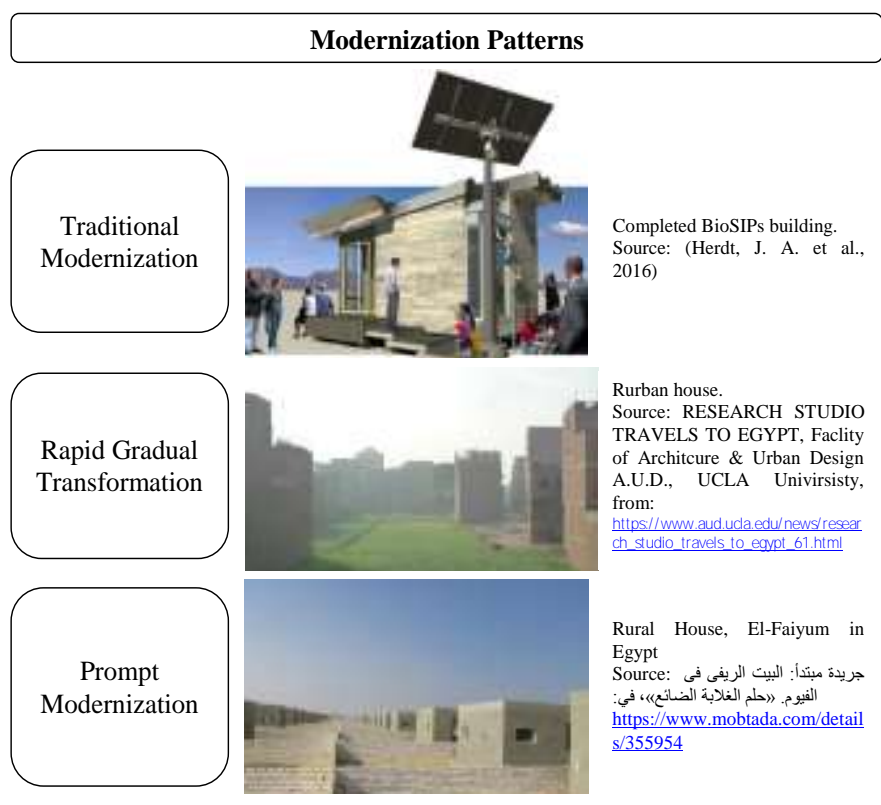

Fig. 1. Modernization patterns in the building constructions from sustainability perspective Source: (Author)

\section{A. Traditional Modernization Pattern}

The materials that are renewed image of traditional, and that does reflect the reality of the sustainability. This material has an ability to exploit natural resources and integration approaches in local planning processes to achieve more environmentally, in addition to improving the level of production and strengthening the elements of organization and management were significant aspect.

This materials can reduces transportation costs and $\mathrm{CO} 2$ emissions, they can include recycled materials, they have a lower environmental impact, they are thermally efficient, they require less energy and they are lower in toxic emissions and they are financially viable [10].

\section{B. Building Materials Resulting from Rapid Gradual Transformation}

The result of the contact of other communities and different cultures can be the replacement of one by the other. These transformations are deeply changing the traditional rural lifestyles of the population and are producing a hybrid settlement pattern, where urban and rural characters melt together [11].

This connection has usually resulted in rapid transmission of building style and materials of construction, such as urbanization of the rural, referred to in numerous literature as "rurbanity". While some of the issues, like changing agricultural systems, are universal, other aspects of the process are specific to certain countries or regions. Accordingly, Egypt rural areas have been dramatically decreasing, while urbanized 
areas expanding and habitats modifying. The process of mixing not only led to the disappearance and of rural forms but also to the emergence of completely new forms of houses, that leads to change of demographic and socioeconomic characteristics.

\section{Prompt Modernization Conception}

This modernization pattern means that it has been planned and imposed largely by intentional government activity, such as, Maspero Triangle District, Cairo and Rural House, El-Faiyum in Egypt, Fig. 2.

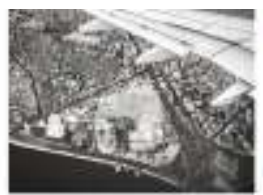

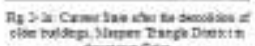

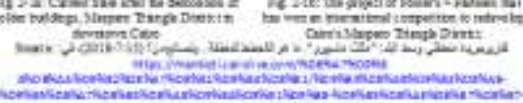

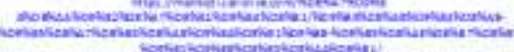
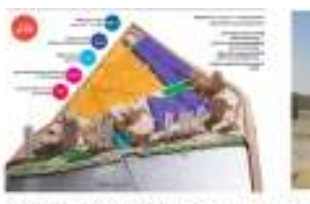

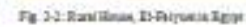

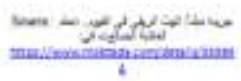

\section{RURBAN AREAS SUSTAINABILITY (Why \& HOW)}

The aim of any sustainable development program of rurban areas should be to achieve the exploitation of local resources, and their fair distribution among the total population, for Egypt cannot afford to let any source of potential wealth untapped, nor to leave people underprivileged [12].

There is a need also to explore the rural communities in the context of seeking to understand the sustainability thoughts. In this context, this study adopts a number of concepts from diverse disciplines such as: Sustainability; Environmental Sustainability; Socio-economic Sustainability; for rural communities, due to its importance in the context of the research topic, as follows (Fig. 3.):

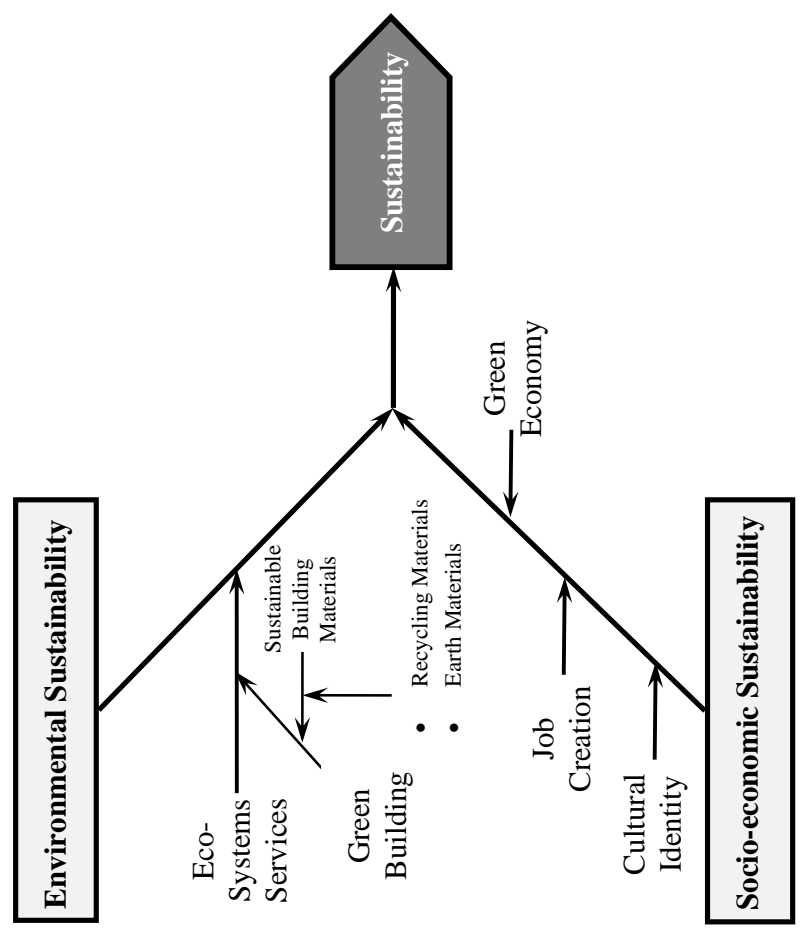

Fig. 3. Hierarchy of sustainability Source: (Author)

\section{A. Sustainable Rurnban Communities}

Sustainability issues have gained great importance over the last decades. Although commonly used sustainability and relatively clearly defined in an environmental context, the concept of sustainability tends to be rather nebulous and confusing in the context of rural socio-economic development [13].

The sustainable development strategy indicated that there should be support rurban communities, to strengthen their economies, provide better quality of life to residents, and build on assets such as traditional main streets, agricultural and working lands, and natural amenities and resources [14].

The overriding objective is to help achieve a positive, lasting legacy of sustainable rurban communities in which people enjoy living and working with a full range of goodquality life and which enhance local landscapes, heritage and biodiversity while meeting the challenges of climate and economic change [15]. It's need for concerted efforts to be economically vibrant and environmentally sustainable [16].

Towards sustainability could be achieved at the village by the most dynamic elements which is a house [17]. In dealing with rurban housing that referred to contrasts in development trends between rural population in some areas and strong pressure for development of housing in other rural areas close to cities and towns [18].

So, within the context of Egyptian rurban, this study brings into focus traditional and modern building materials, specifically mud brick and BioSIPs.

\section{A.1. Mud brick for Rural Communities}

Using mud-brick building materials is one obvious way construction that typically found in old rural areas of Egypt to reduce the cost of poor villagers, Fig. 4.

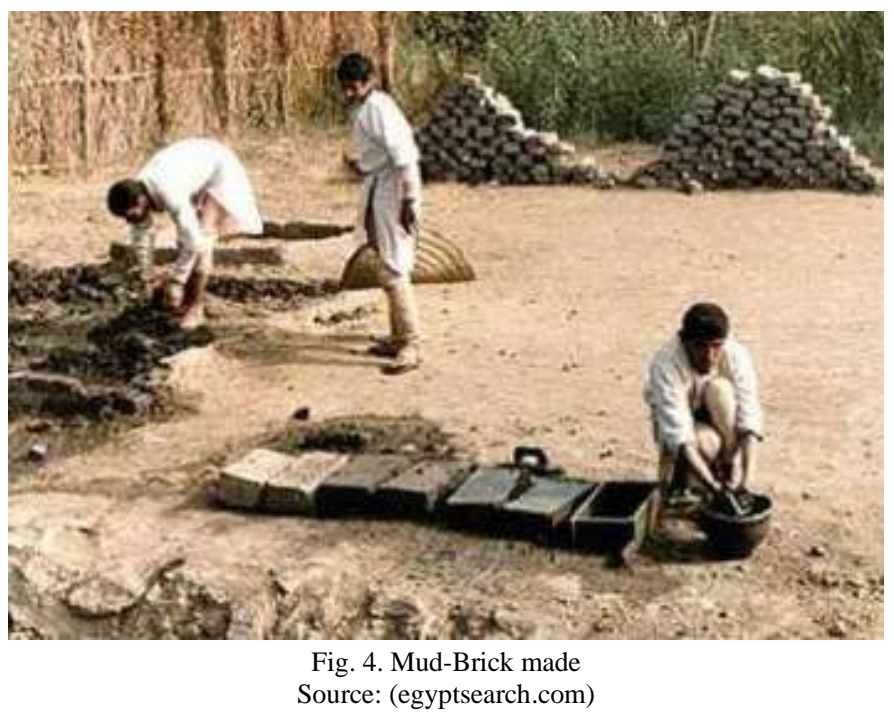

Moreover, it has been proven that mud-brick is optimized for sustainable building since it not only eliminates the cost need for the transportation of imported materials, but also significantly reduces the use of non-renewable, rare and energy intensive products such as lumber, concrete blocks and cement [19]. Figure (5) illustrates a number of examples of mudbrick houses in the Egyptian rural communities. 


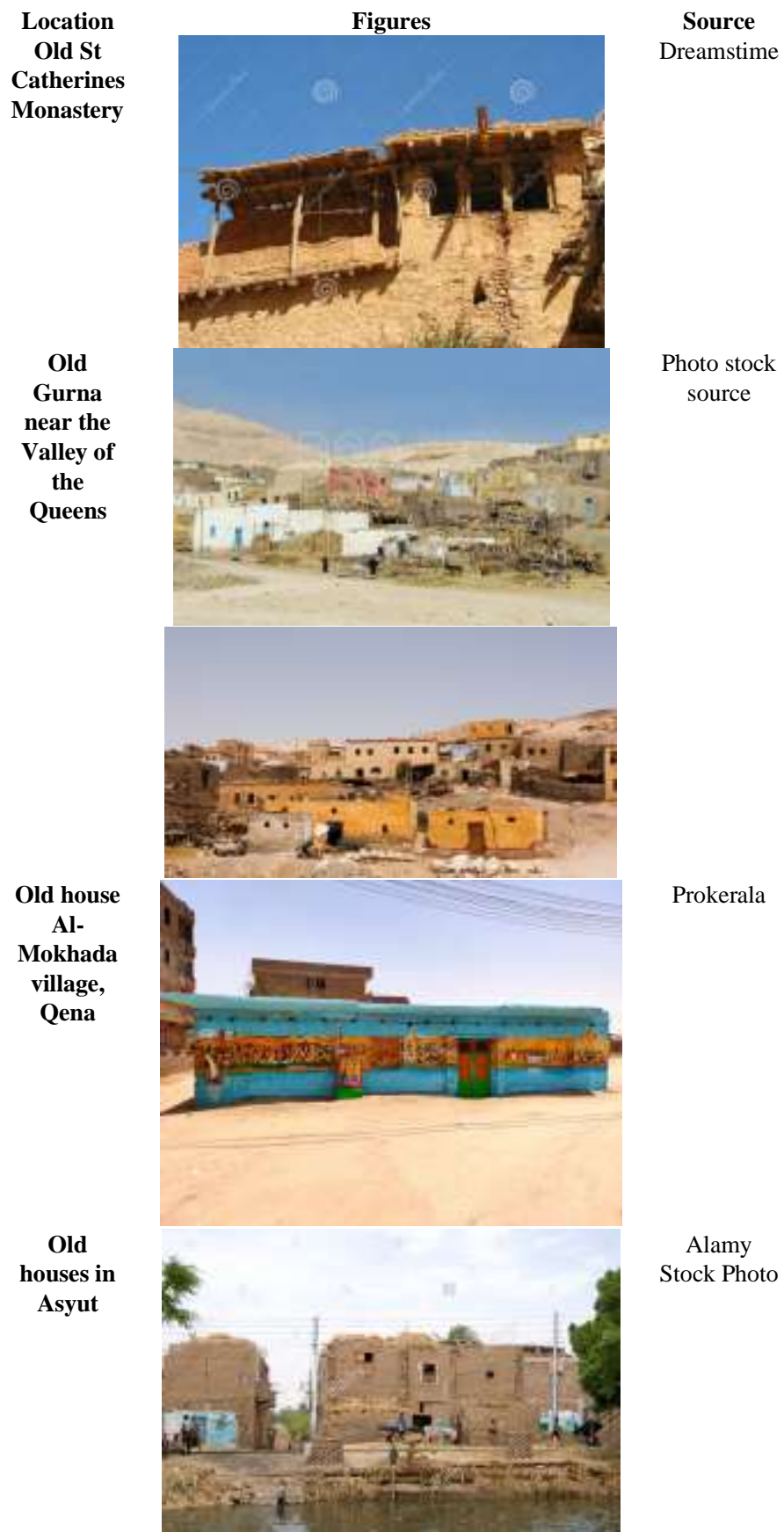

Fig. 5. Old houses in Egyptian rural villages Source: (Author)

Figure (6) illustrates Hassan Fathy's experiment at rural Egypt. Fathy had worked with traditional forms such as domes and vaults by the use of local materials (mud brick) to build low cost housing in the village of New Gourna (west Luxor, Egypt).

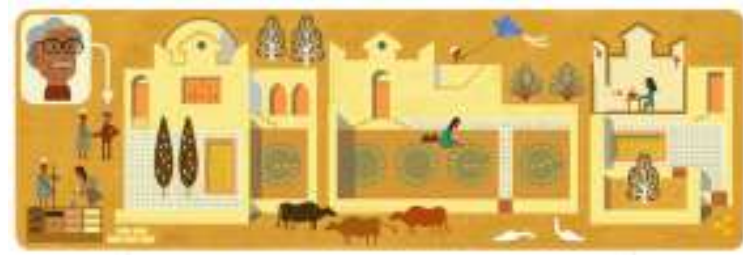

Fig. 6. Hassan Fathy experimental at rural Egypt Source: (Google [20], 2017)

\section{A.2. BioSIPs for Rurban Communities}

In the past, some of Egypt's factories had been making prefabricated house. Figure (7) shows an old advertisement on an Egyptian newspaper published in April 1949 for prefabricated houses. The factory had been promoting types of precast-based housing system, built by non-traditional methods from components made in a factory. It was made from prefabricated building combustible materials or noncombustible materials.

With this announcement it's clear that the prefabricate building can be easily maintained, assembled and disassembled. The project was made evident in the construction of private houses and summer residences located in the suburb of Helwan, in Cairo, Egypt.

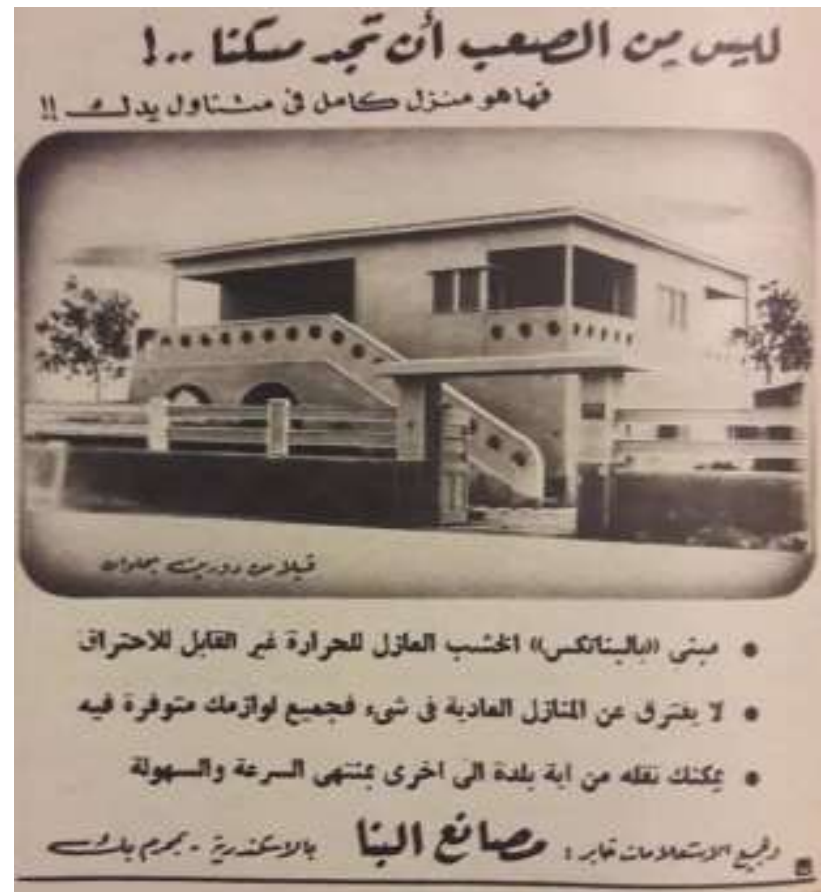

Fig. 7. An old advertisement on Egyptian newspaper for prefabricated houses, 1949.

Source: (Pinterest [21])

Also, the BioSIPs is a prefabricated building material used to construct the walls of the house and produced from composed of recycled; this material can exploit the agricultural waste such as rice straw to build a traditional rural house with low cost and lightweight strategies, Fig. 8.

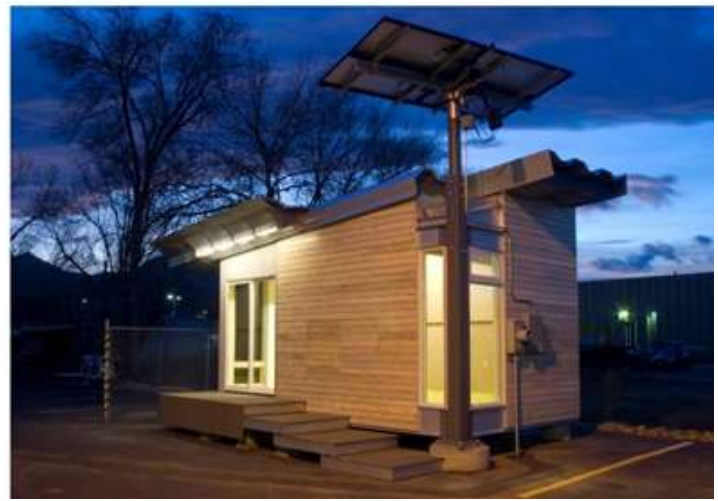

Fig. 8. Completed BioSIPs building Source: (Herdt, J. A. et al., 2016) 
The following explanation will highlight of use the BioSIPs materials in the Egyptian rurban that will contribute toward achieving sustainability pillars.

\section{A.2.1. Socio-Economic Sustainability for Rurban Communities}

Over in the last two decades or so, the whole world has experienced rapid changes and socio-economic transformations, which lead mostly to global resource depletion and pollution that are forcing recognition that existing patterns of development and resource use are not sustainable. The socio-economic transforms influenced and resulted in strict stress, mostly to remote, marginal and rural areas of the world [22].

Even in rural areas within the Egypt, current community life is generally out of touch with tradition. The socioeconomic Egyptian rural patterns are changed, where rapid population growth far outpaces economic. The rapid population growth aggravates poverty and the change of economic activities and changes in land-use. The relationship between population growth and poverty is neither obvious nor well established [23].

Though, the transformations in economic and social tradition structure lead to reduce the farmstead returns, changing in the farming area values. In addition, high rates of joblessness, cause mass exodus of the productive forces and lack of balance in the demographic of rural area [24].

As a result of overlooking the lifestyle of low-income habitants and their socio-cultural needs, extension in the dwelling has become a common phenomenon in rural Egypt in the last decades [25], precede land use changes. Land use transition refers to the changes in land-use morphology over time, and it usually corresponds to a particular socio-economic development phase [26].

The BioSIPs materials concept has been developed in recent years, with the intention of promoting economic development, job creation and for helping the villages to preserve the traditional character of their buildings with low cost.

\section{A.2.2. Environmental Sustainability for Rurban Communities}

The environmental issues are the most important of the pillars of sustainability: socio- economic and environmental sustainability because it requires that natural capital be maintained, both as a provider of resources and as a depository for wastes and is, arguably, a prerequisite for socio-economic sustainability, thus it's impossible to be sustainable without minimize the negative environmental impact by utilizing conjoining all disciplines toward achieving better life.

With the need to help rural communities to address their challenges of environmental problems as the smoke emitted from the rice straw burning that presents grave risks to human health as well as the formulation and realization of a sustainable, it has seemed appropriate to transform the agricultural wastes to building units.

The approach in these units is basically agricultural wastes and called BioSIPs, and there is no person cannot learn and apply method using these wastes and transform to BioSIPs. These materials should help people to take back the responsibility about the environment and to become the rural culture to the context of rural development of their own future. Figure (9) shows the life cycle of BioSIPs materials.

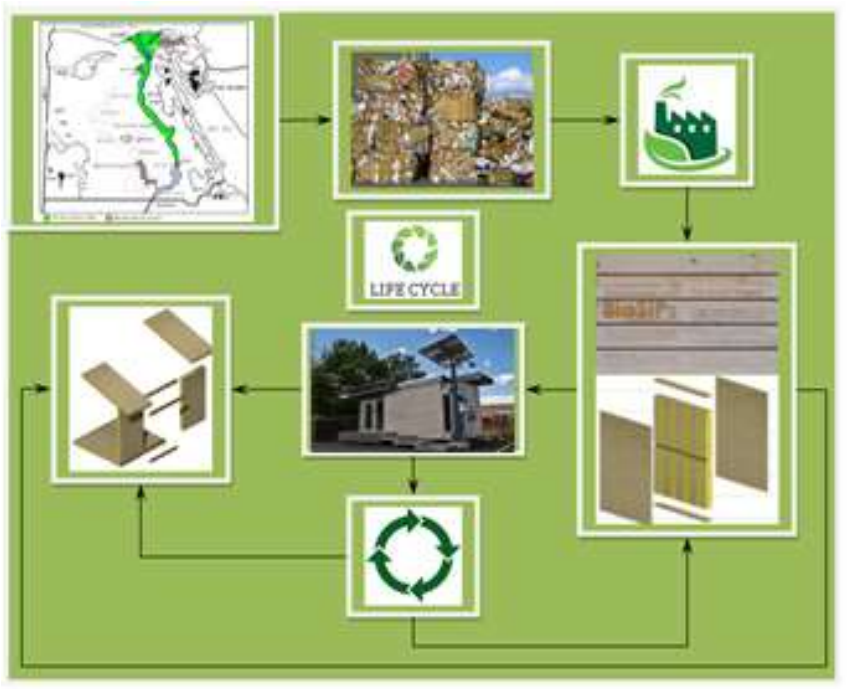

Fig. 9. The life-cycle of a BioSIPs Source: (Author)

We might have to face due to environmental pollution, population growth and poverty in rural Egypt communities towards sustainable development overall, a clean environment and sustainable development is a fundamental right, but can be considered the right of rights because it's pillars that must ensure their availability on the individual's right to a clean and healthy at any community truth seeking achieves human rights system under the overall direction of the political, economic and social humanitarian rights [27].

All these things put the researcher upon awareness of necessary issues of rural Egypt that include the community, economy and the environment. Focus on treatment the environment pollution or if they are forced to pay for the pollution they create.

Table I summarizes some differences between mud-brick and BioSIPs building materials:

\section{TABLE I}

Differences between Mud-Brick and Biosips materials

\begin{tabular}{|c|c|c|}
\hline Material & Mud-Brick & BioSIPs \\
\hline Sustainability & 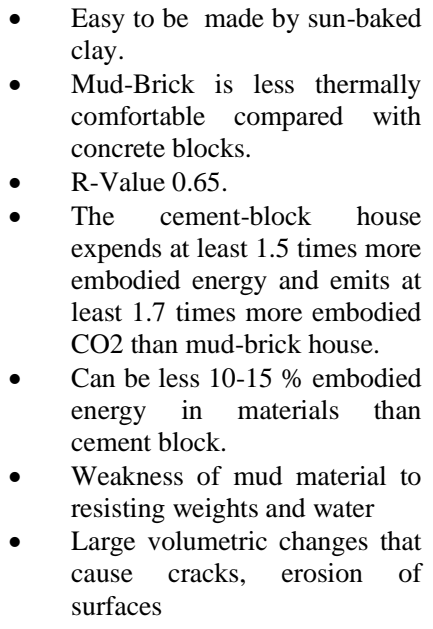 & 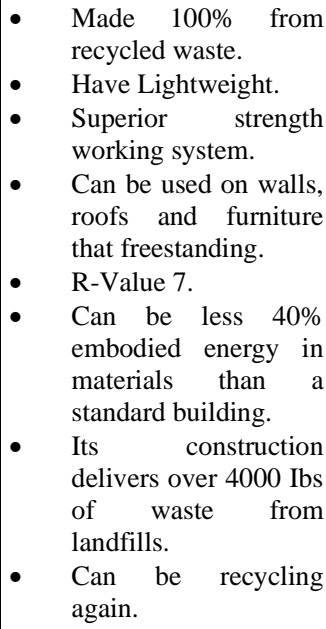 \\
\hline Source & $\begin{array}{ll}- & \text { Henry, A. F. et al, } 2014 . \\
\text { - } & \text { GPRS, 2017. } \\
\text { El-Betar, S. A., } 2017\end{array}$ & $\begin{array}{ll}\text { Herdt, J. A. et al., } \\
2016 .\end{array}$ \\
\hline
\end{tabular}




\section{TRADITIONAL AND MODERN BUILDING MATERIALS IN THE BALANCE}

While the issues of traditional are closely related in many other intangible cultural heritage and local mentality, other aspects of the modernization process are very important of protecting the natural environment on individual, organization controlled or governmental levels.

As for modernity depends on the characteristics that were circulated by members of one generation and produced in a creative way [28].

Among unresolved contradictions between tradition and innovation, for the identity and specific culture qualities, people are becoming better educated, coming into contact with other cultures and technologies, and gradually losing their knowledge of the traditional crafts and agricultural methods that were practised by their ancestors and this is an encouraging change from the traditional way of life to a more modern way of life with a desire for appropriate dwellings [29]. For that to happen, however, it is important for planners and policy makers to develop strategies based on the realities of people's lives [30].

If the most obvious formal difference between the traditional city and the modern city is the difference between a spatial environment and an anti-spatial environment, the fundamental difference between traditional buildings and modern buildings concerns their materials and methods of construction and their corresponding durability (or lack thereof) [31].

Buildings in pre-modern societies for the most part were made with materials locally available and locally produced. These were low embodied energy materials, in several ways [32]:

1- in terms of their inherent properties as materials drawn from the earth and in need of relatively little refinement;

2- in terms of the relative ease with which they were acquired, prepared for use in buildings, and employed in the building construction process;

3 - in terms of the energy required to transport them from their point of origin and manufacture to the building site; and

4- in terms of the energy required to repair and maintain them over time.

Prior to the modern era, admittedly under conditions of scarcity and lacking mechanized means of transportation, human beings typically made buildings characterized by the identity of structure and enclosure: the exterior walls of the building were also part of the structure of the building, typically mud, bricks, blocks or stones piled up on one another in compression.

In contrast, standard practice in today's construction industry is for exterior walls to fill between and/or be attached to a building's steel or concrete structural frame (or its diaphragm of wood or steel studs), a practice generally not as durable as traditional construction because the building's component parts are not integral [33]. The resulting architecture with its minimalism, rigour and dryness of language tries to overcome the limitations and contradictions imposed by economic policy [34].

Moreover, again in contrast to traditional construction, most modern construction employs comparatively highembodied energy materials that are, for now, still relatively easy and inexpensive to manufacture and transport in an era of cheap energy. How long that can continue remains to be seen; but the facts are that traditional construction both employs lower embodied energy materials than modern construction and is generally more durable than modern construction [35].

The following table summarizes the differences between traditional and modern building construction [36]:

TABLE II

DIFFERENCES BETWEEN TRADITIONAL AND MODERN BUILDING CONSTRUCTION

\begin{tabular}{l||l}
\multicolumn{1}{c}{$\begin{array}{c}\text { Traditional mass wall } \\
\text { construction }\end{array}$} & \multicolumn{1}{c}{$\begin{array}{c}\text { Modern cavity wall } \\
\text { construction }\end{array}$} \\
\hline $\begin{array}{l}\text { Relies on the mass of the wall for } \\
\text { 'weatherproofing'. }\end{array}$ & Relies on 'waterproof' materials. \\
\hline $\begin{array}{l}\text { Built with soft, porous, flexible, } \\
\text { 'breathable' materials. }\end{array}$ & $\begin{array}{l}\text { Built with hard, impervious and } \\
\text { inflexible materials. }\end{array}$ \\
\hline $\begin{array}{l}\text { Absorbs moisture and allows quick, } \\
\text { natural drying. }\end{array}$ & $\begin{array}{l}\text { Physical break (cavity) to prevent } \\
\text { moisture transferring to the inside } \\
\text { of building. }\end{array}$ \\
\hline $\begin{array}{l}\text { Relies on natural ventilation to } \\
\text { control the internal environment } \\
\text { and prevent condensation and } \\
\text { mould growth etc. }\end{array}$ & $\begin{array}{l}\text { Relies on mechanical extraction } \\
\text { and physical ventilation to control } \\
\text { the internal environment and } \\
\text { prevent condensation and mould } \\
\text { growth etc. }\end{array}$ \\
\multicolumn{2}{c}{ Source: (Understanding Traditional Materials, in: }
\end{tabular}
http://www.spabfim.org.uk/pages/understanding traditional_materials.html)

In the end, the past does not exist today. Only its traces, buildings, traditions, crafts ... etc. These traces are part of the present. To be part of the future, it is the task to envision how our cultures, traditions and buildings are more than traces of the past. They must be useful, functional and critical resource to better future. Flexibility, enlightened approach to heritage as a future opportunity (economy, investments, and technology) would help with that. Hence, the separation between traditional and modern building materials often is ambivalent, when all pointed in the same direction that will result in greater impact for massive, complex goals such as sustainability development goals.

\section{Conclusion}

The concepts of modern and traditional construction building materials in the rural areas are inherently multifaceted issue that is closely linked to achieving sustainability. If handled well and efficiently, the use of modern materials can be the fuel to achieve sustainability. In other words, there are several types of modernization patterns in building constructions that can be divided into three categories: traditional, rapid gradual transformation, and prompt modernization.

The connection between rural and urban has usually resulted in rapid transmission of building style and materials of construction, such as cement and concrete that replace traditional materials as mud-brick. Mud-brick is known as a sustainable material compared to cement and concrete. In a competence based approach, however, the use of some of the 
modern materials, such as the use of BioSIPs in rurban areas may add another modern dimension of sustainability.

Mud-brick and BioSIPs are sustainable materials that both have low embodied energy. As a conclusion, the use of BioSIPs materials is better than the use of mudbrick, because a BioSIPs building has less embodied energy in materials than mud-brick. In addition, BioSIPs is comparably stronger than mudbrick with better ability of good thermal insulation as well. Based on the above, it is recommend that the government should take immediate steps to examine developmental plans of rurban housing by use of BioSIPs.

The foreseeable problem in such an approach that blends modernization aspects into old ones is awareness among the villagers. Here comes the role of decision makers to urge the importance of environmental preserving to green building achievement. However, the separation between traditional and modern building materials is often ambivalent when all pointed in the same direction, that will result in greater impact for massive, complex goals of advancing sustainability development at the local level.

\section{REFERENCES}

[1] Nicchia, R., KEY TOPICS FOR PLANNING THE SUSTAINABLE GROWTH OF MOZAMBICAN RURAL-TOWNS (167-178), Future Intermediate Sustainable Cities: a message to future generations, The First International Conference on sustainability and future, 2010, BUE, ElSherouk city, Cairo.

[2] Olukoya Obafemi, A. P. and Kurt, S., Environmental impacts of adobe as a building material: The north cyprus traditional building case, Case Studies in Construction Materials Jurnal, Vol. 4 (2016) 32-41, Elsevier.

[3] Monni, G., Traditional and Modern Building Materials. Autarkical Lodging Houses in Carbonia, in: http://www.arct.cam.ac.uk/Downloads/ichs/vol-2-2261-2276-monni.pdf

[4] Olukoya Obafemi, A. P. and Kurt, S., Op. cit.

[5] http://www.climatetechwiki.org/technology/traditional-buildingmaterials-and-design

[6] Ibid.

[7] Gandi, P. K., Social action through law, N.Rai, concept . Co . new Delhi, 1985, p. 7.

[8] Ibid, p. 8.

[9] Ibid.

[10] http://www.sustainabledevelopmentnetwork.com/manual1/Chapter\%203 .pdf

[11] Nicchia, R., Op. cit.

[12] Fathy, H., Architecture for the Poor: An Experiment in Rural Egypt, Chicago: University of Chicago Press, 1973.

[13] Copus, A.K. and Crabtree, J.R., Indicators of socio-economic sustainability: An application to remote rural Scotland, Journal of Rural Studies, Vol. 12 (1996) 41-54, Elsevier.

[14] https://www.epa.gov/sites/production/files/documents/2011_11_supporti ng-sustainable-rural-communities.pdf

[15] Copus, A.K. and Crabtree, J.R., Op. cit.

[16] https://www.epa.gov/sites/production/files/documents/2011_11_supporti ng-sustainable-rural-communities.pdf

[17] ASHRAE Green Guide: Design, Construction, and Operation of Sustainable Buildings, Fourth Edition, 2013.

[18] Copus, A.K. and Crabtree, J.R., Op. cit.

[19] Fathy, H., Op. cit.
[20] Google celebrates Hassan Fathy, accessed on March $23^{\text {th }} 2020$.

[21] https://www.pinterest.com/pin/127015651974659836/ accessed on June $30^{\text {th }} 2020$.

[22] Long, H., et al., Socio-economic development and land-use change: Analysis of rural housing land transition in the Transect of the Yangtse River: China, Journal of Land Use Policy, Vol. 24 (2007) 141-153, Elsevier.

[23] Poverty and Population Growth - UNEP, from http://www.unep.org/training/programmes/Instructor\%20Version/Part 2 /Activities/Human_Societies/Population/Supplemental/Poverty and Po pulation_Growth.pdf

[24] Long, H., et al., Op. cit.

[25] Ahmed, A. M. A. et al., A dialogue between housing designers and lowincome habitants, from http://www.cpasegypt.com/pdf/Ayman\%20Asem/Research/A_dialogue_between_housin g designers and low\%20income\%20habitants final ayman assem.pdf

[26] Long, H., et al., Op. cit.

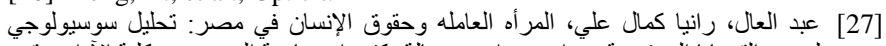

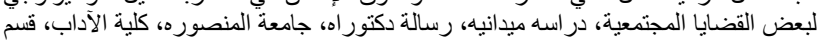

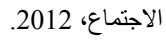

[28] Rashed, A. Y., Why the First International Conference of Sustainability and the Future is entitled: Future Intermediate Sustainable Cities: A Message to Future Generations (35-45), Future Intermediate Sustainable Cities: a message to future generations, The First International Conference on sustainability and future, 2010, BUE, ElSherouk city, Cairo.

[29] Mrema, G.C., Rural structures in the tropics: design and development, Rome: FAO, 2011, Ch. 11.

[30] Mylott, E., Urban-Rural Connections: A Review of the Literature, in: http://ir.library.oregonstate.edu/xmlui/bitstream/handle/1957/10574/Urb an-RuralConnectionsLitReview.pdf

[31] Architecture and Urbanism: Traditional vs. Modern, in: http://www.frontporchrepublic.com/2014/07/architecture-urbanismtraditional-vs-modern/

[32] Ibid.

[33] Ibid.

[34] Monni, G., Op. cit.

[35] Architecture and Urbanism: Traditional vs. Modern, Op. cit.

Understanding Traditional Materials, in:

[36] http://www.spabfim.org.uk/pages/understanding traditional materials.ht $\underline{\mathrm{ml}}$

\section{Title Arabic:}
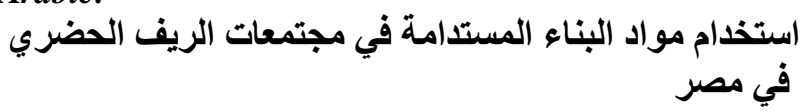

Arabic Abstract:

إن استخدام المواد التقليدية في البناء في الريف المصري لم يكن أكثر من

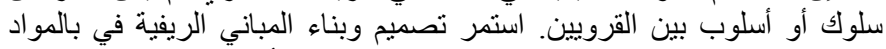

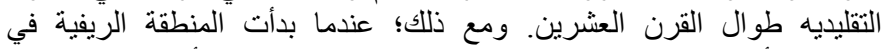

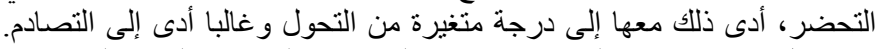

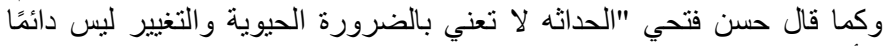

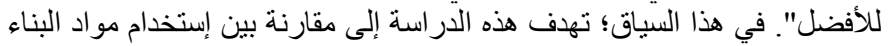

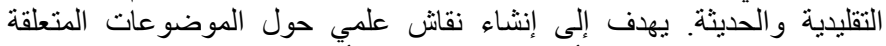

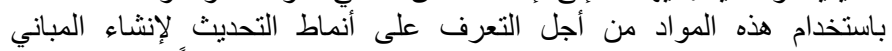

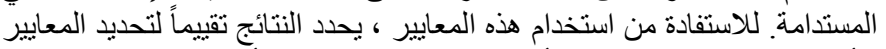

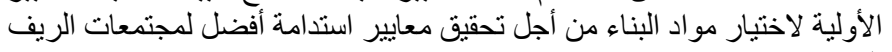

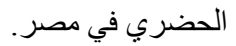

